\title{
Dry season diet composition of four-horned antelope Tetracerus quadricornis in tropical dry deciduous forests, Nepal
}

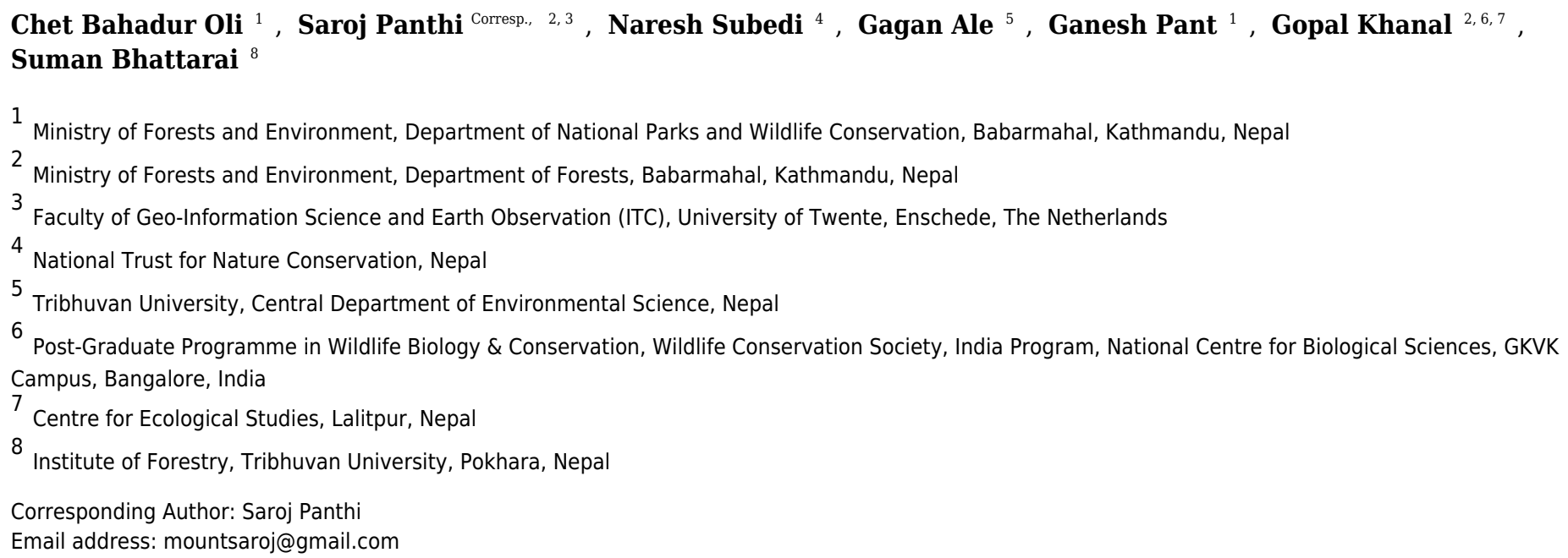

It is essential to assess the feeding strategies of threatened species during resourcescarce seasons to understand their dietary niche breadth and inform appropriate habitat management measures. In this study, we examined the diet composition of Four-horned antelope (FHA)Tetracerusquadricornis, one of the least studied ungulate species, in Banke National Park, Nepal. A total of 53 fresh pellet groups were collected between December 2015 and January 2016 and analyzed using micro-histological fecal analysis technique. First, we prepared 133 micro-histological photographs of different parts of 64 reference plant species. Then we compared 1,590 fragments of 53 fecal samples with photographs of reference plants to assess the percentage of occurrence of different plant species in FHA diet. A total of 30 plant species belonging to 18 different families were identified in fecal samples. Chi-square goodness of fit tests showed that FHA appeared not to feed all plant uniformly. Out of 1,520 identified fragments in fecal samples, 1,300 were browse species and 220 were grass species. Browse represented $85.5 \%$ of the identified plant fragments suggesting that FHA might be adopting a browser strategy at least during winter when grasses are low in abundance and their nutritive quality is poor. Tree species had the highest contribution in the diet $(46.55 \%)$ followed by shrubs $(24.52 \%)$. The family Gramineae was consumed in the highest proportion (27.68 \%) followed by Euphorbiaceae (11.95\%). Overall, our results suggest that FHA has the feeding plasticity to adapt to resource fluctuation. Based on the findings of this study, we recommend that dicot plant species particularly, fruit trees and shrubs, which are the major source of nutrients for FHA 
during resource-lean, dry season be conserved and natural regeneration of these taxa be promoted. 


\section{Dry season diet composition of four-horned antelope Tetracerus quadricornis}

\section{2 in tropical dry deciduous forests, Nepal}

3

4 Chet Bahadur Oli ${ }^{1}$ Saroj Panthi ${ }^{2,3^{*}}$ Naresh Subedi ${ }^{4}$ Gagan Ale ${ }^{5}$ Ganesh Pant ${ }^{1}$ Gopal Khanal ${ }^{2,6,7}$

5 Suman Bhattarai ${ }^{8}$

6

7

1. Ministry of Forests and Environment, Department of National Parks and Wildlife Conservation, Babarmahal, Kathmandu, Nepal

2. Ministry of Forests and Environment, Department of Forests, Babarmahal, Kathmandu, Nepal

3. Faculty of Geo-Information Science and Earth Observation (ITC), University of Twente, Hengelosestraat 99, P.O. Box 217, 7500 AE, Enschede, The Netherlands

4. National Trust for Nature Conservation, Nepal

5. Central Department of Environmental Science, Tribhuvan University, Kathmandu Nepal

6. Post-Graduate Programme in Wildlife Biology \& Conservation, Wildlife Conservation Society, India Program, National Centre for Biological Sciences, GKVK Campus, Bellary Road, Bangalore 560065, India

7. Centre for Ecological Studies, Lalitpur, Nepal

8. Institute of Forestry, Tribhuvan University, Pokhara, Nepal

\footnotetext{
* Corresponding author: Saroj Panthi (email: mountsaroj@gmail.com)
} 


\section{Abstract}

26 It is essential to assess the feeding strategies of threatened species during resource-scarce seasons

27 to understand their dietary niche breadth and inform anpropriate habitat management measures.

28 In this study, we examined the diet composition of Four-horned antelope

29 (FHA) Tetracerus quadricornis, one of the least studied ungulate species, in Banke National

30 Park, Nepal. A total of 53 fresh pellet groups were collected between December 2015 and

31 January 2016 and analyzed using micro-histological fecal analysis technique. First, we prepared

32133 micro-histological photographs of different parts of 64 reference plant species. Then we

33 compared 1,590 fragments of 53 fecal samples with photographs of reference plants to assess the

34 percentage of occurrence of different plant species in FHA diet. A total of 30 plant species

35 belonging to 18 different families were identified in fecal samples. Chi-square goodness of fit

36 tests showed that FHA appeared not to feed all plant uniformly. Out of 1,520 identified

37 fragments in fecal samples, 1,300 were browse species and 220 were grass species. Browse

38 represented $85.5 \%$ of the identified plant fragments suggesting that FHA might be adopting a

39 browser strategy at least during winter when grasses are low in abundance and their nutritive

40 quality is poor. Tree species had the highest contribution in the diet $(46.55 \%)$ followed by

41 shrubs $(24.52 \%)$. The family Gramineae was consumed in the highest proportion $(27.68 \%)$

42 followed by Euphorbiaceae (11.95\%). Overall, our results suggest that FHA has the feeding

43 plasticity to adapt to resource fluctuation. Based on the findings of this study, we recommend

44 that dicot plant species particularly, fruit trees and shrubs, which are the major source of

45 nutrients for FHA during resource-lean, dry season be conserved and natural regeneration of

46 these taxa be promoted. 


\section{Introduction}

Knowledge of the diet composition of endangered wildlife species is very important to

understand foraging ecology and to devise conservation management actions for their long-term

persistence (Belovsky 1997; Ahrestani et al. 2016). Such knowledge is particularly important for ungulates in seasonal environments (Parker et al. 2009) where resource availability is pulsed in summer and scarcity is particularly acute during the arid winter season (Styles \& Skinner 1997; Ahrestani et al. 2012). This seasonal flux in quality and quantity of resource availability (e.g., forage) often has nutritional costs for ungulates (Parker et al. 2009). For example, reduced availability of preferred forage has been found to alter the composition of graminoid and browse Q

in the diet negatively influencing the maintenance of body mass of American elk Cervus elaphus

60 during winter (Christianson \& Creel 2009). In the Mediterranean region, hares were found to eat

61 herbs (preferred food) in the wet season but increase their diet breadth in the dry season by

62 consuming herbs, fruits, and grains (Sokos et al. 2015). In the Indian trans-Himalaya, a medium-

63 sized ungulate grazer, the blue sheep bharal, (Pseudois nayaur) was found to have a mixed diet

64 (mainly browse) during resource-limited winter seasons due to reduced availability of

65 graminoids, resulting from competition with domestic livestock (Mishra et al. 2004;

66 Suryawanshi et al. 2010). Change in diet balance affects reproduction, growth, and survival of

67 animal influencing life history parameters such as body mass of adult females which correlates

68 with vital rates like birth mass, growth rates and survival of young (Pekins et al. 1998). 
69 Understanding the diet composition of a species during resource-lean season is therefore critical

70 to understand diet plasticity and inform forage management measures.

71 The four-horned antelope (FHA) Tetracerus quadricornis is a medium-sized, solitary

72 ungulate (adult shoulder height $55-65 \mathrm{~cm}$, and weight $18-21 \mathrm{~kg}$ at) endemic to the Indian sub-

73 continent (Leslie \& Sharma 2009). It is widely but patchily distributed with fragmented

74 populations in dry deciduous forests from the Himalayan foothills in Nepal to the Gangetic

75 floodplains and the Peninsular mainland in India (Rahmani 2001; IUCN SSC Antelope Specialist

76 Group 2017). Estimates suggest that fewer than 10,000 FHA remain in the wild (IUCN SSC

77 Antelope Specialist Group 2017). However, the population of FHA is suspected to have declined

78 throughout its range, mainly due to habitat loss and fragmentation (Sharma et al. 2009).

79 Although presently it is classified under the 'Vulnerable' category, the assessment of the IUCN

80 Red List of threatened species states that "no subpopulation is estimated to contain more than

811000 mature individuals and it is possible that it is already close to reaching the Endangered

82 category" (IUCN SSC Antelope Specialist Group 2017). In Nepal, FHA is reported to occur in

83 dry deciduous hill sal Shorea robusta and mixed Shorea-Terminalia forests in four protected

84 areas of Nepal: Bardia National Park (Pokharel 2010; Kunwar et al. 2016), Chitwan National

85 Park (Pokharel et al. 2015b), Parsa National Park and Banke National Park (DNPWC 2017b). Its

86 distribution is restricted to open canopy dry deciduous mixed forests, characterized by short

87 grassland patches, sparse understory and undulating terrain (Krishna et al. 2009; Sharma et al.

88 2009; Baskaran et al. 2011). It has been found to be sympatric with barking deer Muntiacus

89 muntjak in the monsoon season in Nepal (Pokharel et al. 2015a). Nepal's National Parks and

90 Wildlife Conservation Act, 1973 has listed this species under the protected species list,

91 prohibiting hunting (GoN 1973). 
93 (Krishna et al. 2008; Sharma et al. 2013; Pokharel et al. 2015b) and habitat ecology (Sharma et

94 al. 2009; Baskaran et al. 2011) with few studies on its feeding ecology (Sharma et al. 2009;

95 Baskaran et al. 2011; Pokharel et al. 2015a; Kunwar et al. 2016). Although these previous

96 studies have been useful in improving our understanding of the natural history, ecology and

97 behavior of the species, we still know little about the responses of the species to changes in

98 habitat components, interspecific interaction with other sympatric species, habitat requirements

99 and population abundance. Since it continues to lose its habitat to agricultural development,

100 livestock grazing, fire, and encroachment by invasive species like Banmara (Lantana camara)

101 (Krishna et al. 2009), information on diet composition is particularly important for conservation

102 management interventions. Previous studies showed that FHA predominantly consumes a

103 browse-dominated diet, especially with highly nutritious plant parts such as fruits, flowers and

104 fresh leaves (Baskaran et al. 2011; Pokharel et al. 2015a; Kunwar et al. 2016). In summer, when

105 the availability of grass is high, FHA has been found to increase its diet breadth and consume

106 grass species as well as the forb species Ageratum conyzoides (Kunwar et al. 2016). Cynodon

107 dactylon and Acacia nilotica were identified as the main winter dietary species of FHA in

108 Madhya Pradesh, India (Sharma et al. 2009). The browse to grass ratio was high in the dry winter

109 season and low in the wet monsoon season in the diet of FHA in Bardia, Nepal (Kunwar et al.

110 2016).

111 While previous studies on food habits of FHA have provided important insights into its

112 seasonal pattern of feeding revealing its generalized feeding strategy, more in-depth and rigorous

113 studies are needed to confirm if the findings of these species are applicable to all habitat

114 conditions. Most of the previous studies had a small sample size (e.g., 20 pellet samples for dry 
115 winter season feeding analysis; Kunwar et al. 2016) making it difficult to draw any broad

116 generalization of their diet patterns. Studies with sufficient sample size are needed not only to

117 understand the variability present in the diet but also to ensure the validity of broader inferences.

118 It has been documented that an ungulate species may be forced to consume different food species

119 in different sites due to difference in food density and composition as well as the density of other

120 co-occurring species, habitat, predation risk, monsoon seasonality and competition with

121 sympatric species including livestock (Fritz et al. 1996; Wilsey 1996; Valeix et al. 2009). Site-

122 specific studies on diet composition can thus be very useful not only in informing site-specific

123 habitat management and species conservation measures but also in improving our understanding

124 of the species feeding ecology in diverse habitat types and developing a general theory. Banke

125 National Park, which lies in the foothills of the Siwalik mountain range, has diverse habitat types

126 from pure Shorea robusta forests to mixed dry deciduous Shorea-Terminalia-Albizzia forests.

127 Before it was established as a national park in 2010, it was managed as a production-forest to

128 produce timber and fuel wood. Livestock grazing and human use of the landscape for the

129 collection of fodder and non-timber forests products was also common under previous

130 management regime. The density of other sympatric ungulates (e.g., barking deer, spotted deer

131 Axis axis) and the density of potential predators is less in comparison to other national parks

132 where FHA occurs (e.g., Bardia National Park). These peculiarities offer a unique opportunity to

133 assess if food habits of FHA in this national park are consistent with findings from other

134 protected areas.

135 In this study, we examined the dietary composition of FHA in Banke National Park,

136 Nepal, which is the first of its kind in this park. We specifically examined whether FHA

137 consumes all potential forage plant species equally when the availability of such species is low. 
138 We hypothesized that if FHA is a selective browser, it would include a high proportion of

139 browse in its diet. We also predicted that if this animal has a more flexible generalized grazer-

140 browser mixed feeding strategy? he findings are useful for the government of Nepal and

141 conservation stakeholders for planning forage and habitat management measures.

142

143 Materials and Methods

144 Study area

145 This work was conducted with research permission (1082-2072-9-2) from Department of

146 National Parks and Wildlife Conservation for research in Banke National Park (N 275' $13^{\prime \prime}$ to N

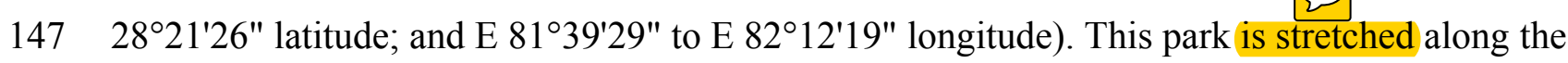

148 Churia foothills of the western part of the Terai Arc Landscape of Nepal (Figure 1). Established

149 in 2010 as an effort to conserve the tropical deciduous ecosystem and to double the tiger

150 Panthera tigris population in Nepal, it covers an area of $550 \mathrm{~km}^{2}$ in its core zone and $343 \mathrm{~km}^{2}$ in

151 its buffer zone (DNPWC 2017a). The park connects the Bardia National Park in the west and

152 Suhelwa Wildlife Sanctuary of India through the forests in the southern part, with its buffer zone.

153 Its elevation ranges between 153 to $1,247 \mathrm{~m}$ above the mean sea level. Mean maximum

154 temperature is around $40^{\circ} \mathrm{C}$ in summer but drops to very low during winter. Seasons are of four D

155 types, monsoon (Jun-September; the wet season with abundant rainfall), autumn (Oct-Nov), dry

156 winter (Dec-Feb) and spring (Mar-May). The park contains eight ecosystem types: Shorea

157 robusta forest, deciduous Riverine forest, savannas and grasslands, mixed hardwood forest,

158 floodplains, Bhabar and foothills of Chure range (DNPWC 2017a).

159 Figure 1: The smaller map with the boundary of Nepal shows the protected areas of Nepal.

160 Different colors denote the different categories of the protected areas. The large map is the 
161 study area, Banke National Park, which shows the core zone and buffer zone of the

162 national park as well as the locations of sample collection (source of shape file: UNEP-

163 WCMC\& IUCN, 2017).

\section{Data collection}

Field surveys were conducted between December 2015 and January 2016 to collect the

167 pellets of FHA and vegetation samples. Before going to the field for data collection, 22 key

168 informant interviews were conducted with local people and park staff to identify the potential

169 habitats of FHA. Based on information obtained from the key informant interview, we identified

170 FHA hotspots and randomly laid transects of $500 \mathrm{~m}$ long and $20 \mathrm{~m}$ width in the map. Transect

171 surveys are widely used method to collect fecal samples of ungulates (Pokharel et al. 2015a;

172 Kunwar et al. 2016). The survey team, which included the first author, three field assistants and

173 an expert from National Trust for Nature Conservation - Bardia Conservation Program walked

174 along the 40 transects to collect the pellets samples. Wherever we recorded pellets, we

175 established a plot of $10 \mathrm{~m}$ X $10 \mathrm{~m}$ around the pellet and collected the fecal samples and sample

176 of all species of vegetation within these plots for lab analysis. This is Tecommended and widely

177 used plot size for the study of dietary patterns of wild animals (Schemnitz 1980; Panthi 2011;

178 Panthi et al. 2012; Aryal et al. 2015a). Leaves, twigs, fruits, and barks of all plants were 179 collected.

180 The pellets of FHA were identified checking the shape, size, and texture of pellets

181 following Pokharel (2010) who has confirmed size and shape details of FHA pellets by installing

182 camera traps in the suspected middens of FHA in Bardia National Park. These FHA pellets were

183 available as a reference for the verification of the pellets at Bardia National Park. We hired those 
Q

184 reference pellets along with a trained wildlife technician (Mr. Binti Ram Tharu) from NTNCS

$185 \mathrm{BCP}$ to help to minimize misidentification of pellets during the field survey. In drier habitat, the

186 pellets can decay very rapidly, and further laboratory analysis can be difficult (Jung \& Kukka

187 2016) so fresh pellets, not more than seven days old, were identified based on texture and

188 moisture content. We randomly sub-sampled $25 \%$ each sample group for further analysis.

189 These samples were air dried for five days in the field to remove moisture and prevent fungal

190 growth. The collected plant samples were preserved in the herbarium and stored in the well

$$
\text { P }
$$

191 ventilated dry room of Banke National Park Office, Overy Banke and sent to Central Department

192 of Botany, Tribhuvan University, Kathmandu for further verification.

194

195

196

197

\section{Micro-histological analysis}

Micro-histological fecal analysis technique was used to determine plant composition of FHA fecal matter (Sparks \& Malechek 1968; Holechek \& Gross 1982). This method is widely used as a diet analysis tool to investigate the dietary composition of ungulates (Shrestha et al. 2005; Nagarkoti \& Thapa 2007; Aryal et al. 2015b; Jung et al. 2015; Wangchuk et al. 2016). This method involves microscopic recognition of indigestible plant fragments of plant groups and preparation of reference and fecal slides and their interpretation. Samples of plant parts were dried in the oven at $60{ }^{\circ} \mathrm{C}$ in the laboratory and grinded sengrately into powder using an electric blender. The powder of each sample was sieved by using 212 microns mesh size.

The micro-histological slides of reference plants, as well as fecal sample slides, were<smiles>C1C2CC1C2</smiles>
prepared using the methods of Norbury (1988). In this method Tererence samples or fecal samples were placed in Petri dishes and bleached with $50 \mathrm{ml}$ of 4\% sodium hypochlorite for 6-24 hours at room temperature to remove mesophyll tissue and to render the epidermis identifiable. 
207 The bleached contants were then rinsed well in a sieve, and then the rinsed fragments were<smiles>[CH]1C=C1</smiles>

208 treated with few drops of staining substance-gentian violet solution $(1 \mathrm{~g} / 100 \mathrm{ml}$ water $)$ for 10

209 seconds and again well rinsed. The stained fragments were mounted on standard microscope

210 slides in a DPX Mountant medium and covered with a cover slip (Norbury 1988). Both reference

211 slides and fecal pellet slides were observed immediately after preparation at magification 400X

212 with a digital microscope, and each fragment was auto-photographed using bel photonics

213 (Norbury 1988; Panthi et al. 2015). A diet analysis expert (Mr. Binod Shrestha) trained the first

214 and fourth authors to identify the plant fragments. A total of 133 micro-histological photographs

215 of different features of 64 plant species were prepared for the reference library. For each sample,

21630 non-overlapping and distinguishable fragments were observed by moving the slides from left

217 to right in the microscope. Specific histological features such as cell wall structure, shape and

218 size of cells, trichomes; and shape and size of stomata were identified as key features to match

219 the features of fecal plant fragments with reference plant (Panthi 2011; Aryal et al. 2012).

220

\section{Data analysis}

222 The plant fragments identified from the micro-histological analysis of the pellet samples were

223 assigned into one of the following four levels of classification with different categories under

224 each classification: (1) growth form: (i) grasses, (ii) forbs, (iii) shrubs, (iv) climbers (vine plants)

225 and (v) trees; (2) class: (i) monocots and (ii) dicots; (3) family; and (4) species. The idea behind

226 this classification was to assess the relative contribution of different categories of plant taxa

227 under each classification to the diet of FHA. We added the total number of fragments in each<smiles>[C-]1C=C1</smiles>

228 species and then calculated the proportion of each group. 
$\Omega$

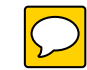

229 Diet composition was expressed as the percentage of occurrence of plant species $(\mathrm{O} \%)$

230 (Cavallini \& Lovari 1991).

231

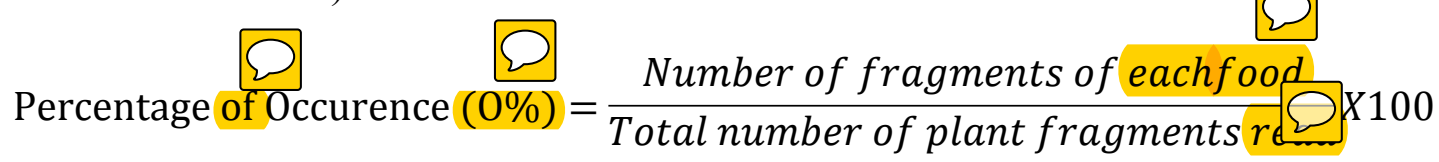

232 We performed the goodness of fit Chi-square test to identify whether FHA ate all plants

233 uniformly. Our research hypothesis was that FHA would not eat all plants species, family,

234 growth form (grass, forb, cliperer, shrub, and tree) and class (monocot and dicot) uniformly. We

235 also hypothesized that FHA is a browser during winter. All tests were performed using Microsoft

236 Excel and R software version 3.4.1 (R Core Team 2013).

237

238 Results

239 A total of 1,590 plant fragments from 53 pellet samples were analyzed through micro-

240 histological technique. Out of the total plant fragments, 70 were unidentified, and these were

241 excluded from statistical analysis. A total of 30 species belonging to 18 different families were

242 identified in the pellets of FHA. Out of 30 species, FHA diet included 14 tree species, eight

243 shrubs, two forbs, five grasses, and one climber (Table 1). The dicot shrub species Phyllanthus

244 emblica had the highest percentage of occurrence in FHA diet (6.92\%) whereas the dicot shrub

245 Clerodendrum viscosum was the least contributor to the diet (0.94\%). FHA appeared not to feed

246 all plant species uniformly $\left(\chi^{2}=312.56, \mathrm{df}=29, \mathrm{p}<0.001\right)$ at the species level. Similarly, at the

247 family level, FHA did not consume all plant families uniformly $\left(\chi^{2}=1982.41, \mathrm{df}=17, \mathrm{p}<0.001\right)$.

248 The family Gramineae which consists of 9 species contributed $27.68 \%$ of the diet whereas

249 Verbenaceae contributed anly $0.94 \%$ of the diet (Table 1). At the growth form level, FHA did

250 not consume all growth form (grass, forb, climber, shrub, and tree) uniformly $\left(\chi^{2}=1001.71, \mathrm{df}=4\right.$, 
$251 \mathrm{p}<0.001)$. In general, trees constituted a large proportion of diet contributing $46.55 \%$, followed

252 by shrubs $(24.52 \%)$, grasses (13.84\%), forbs $(8.18 \%$ and climber $(2.52 \%)$ (Table 1$)$.

253 Similarly, FHA did not have the equal choice at class (monocotyledonous and

254 dicotyledonous $)$ level $\left(\chi^{2}=229.01, \mathrm{df}=1, \mathrm{p}<0.001\right)$. A total of $66.36 \%$ of FHA's diet was

255 composed of dicotyledonous plants, and $29.25 \%$ of FHA's diet was covered by

256 monocotyledonous. Only $4.4 \%$ of the diet of the FHA remained unidentified during this study.

257 The study identified 1,300 fragments of browse (forbs, climbers, shrubs, and trees) and 220

258 fragments of grass in FHA's diet. The ratio of browse to grass was found to be $85.53 \%: 14.47 \%$,

259 showing a strong affinity towards browse plant species in the dry season.

260 Table 1: Percent composition of various plant categories identified in pellets of FHA

262 Discussion

263 Assessment of the dietary choices of a species during low resource availability period is

264 critical to understand its foraging plasticity andinform subsequent habitat and forage

265 management measures. In this study, we studied the winter season food habit of four-horned

266 antelope, a sparsely distributed yet threatened species native to Nepal and India (IUCN SSC

267 Antelope Specialist Group 2017), based on micro-histological analysis of the collected fecal

268 pellet samples. We hypothesized that if FHA is a selective browser during winter, it should show

269 evidence of selectively foraging on browse in its diet.

270 Our result shows that dicots had a significantly higher percentage of occurrences in FHA

271 pellets than monocots (suggesting that FHA might be adopting a browser strategy at least during

272 winter when graminoids and grass species are low in abundance). Plant species differ in protein

273 and fiber contents which influences animals' food choice (Klaus-Hügi et al. 1999). Smaller 
274 antelopes have smaller stomachs compared to larger ruminants but have high metabolic

275 requirements. This prohibits them fram feeding large quantities of coarse grass species that are

276 high in fiber and low in protein contents (Owen-Smith 1992). In dry deciduous tropical forests,

277 graminoids lose their palatability and nutritive quality during the dry season in comparison to

278 wet season (Sukumar 1989; Baskaran 1998). This could probably explain why monocots were

279 not eaten as much as dicots. Berwick (1974) and Sharma et al. (2009) concluded that FUA is a

280 selective feeder. The food selectivity hy FHA may result from nutritional requirements, they

281 need to decrease fiber intake, and maximization of protein intake in order to increase

282 digestibility.

283 Our results support the hypothesis that FHA adopts a browser strategy during winter, but

284 we cannot rule out the possibility that $\mathrm{FHA}$ is a mixed feeder with substantial feeding plasticity

285 to balance nutritional requirements. Presence of grasses in $14.3 \%$ of plant fragments suggests

286 that grasses also have a substantial contribution to FHA diet. Our results of higher contribution

287 of browse are consistent with the findings of Kunwar et al. (2016) who reported that browse

288 constituted nearly two-thirds (66.95\%) of the overall diet while grass species occurred only

$28913.68 \%$ (the rest, 19.77\% remained unidentified). A study from India has, however, shown that

290 FHA had more or less equal proportion of grass and browse in FHA diet in the winter season (14

291 grass, five herbs, four trees and one shrub) (Baskaran et al. 2011). This discrepancy in findings

292 could be due to differences in study location, sample size and the high proportion of unidentified

293 plants in their analysis. Baskaran et al. (2011) had $48 \%$ of the plant remains in their FHA fecal

294 samples which could not be identified whereas in our study we have only $4.40 \%$ of the plant

295 fragments that remained unidentified. 
298 (Table 1). The shrub Phyllanthus emblica of the family Euphorbiaceae occurred most frequently

299 (6.92 \%) in FHA diet. In their study in Bardia National Park, Kunwar et al. (2016) identified

300 Berlaria cristata as the shrub species with the highest frequency of occurrence $(5.33 \%$ of total

301 fragments identified) in FHA diet in the winter season. The cafeteria experiments of Berwick

302 (1974) in Gir forest ecosystem, India, and Sharma et al. (2009) in Van Vihar National Park cum

303 Zoo in Bhopal, India, showed that Zizyphus mauritiana contributed most to the diet of captive

304 FHAs in winter. Our study also revealed a moderate contribution (4.40\%) of Zizyphus

305 mauritiana. Although Zizyphus mauritiana is highly palatable, its thorns inhibit its consumption

306 in the natural habitats (Berwick 1974). The FHAs in the Banke National Park do not appear to

307 selectively consume towards climber species as indicted relatively low percentage of occurrence

308 in fecal samples.

$309 \quad$ FHA distribution is determined by the tree species richness in India, and thus tree species

310 richness has been considered as a good indicator of the FHA distribution (Sharma et al. 2009). In

311 our study, tree species constituted a substantial proportion of FHA diet. On the whole, trees

312 contributed the highest proportion (46.54\%) of diets of FHA followed by shrubs $(24.53 \%)$,

313 grasses (13.84\%), forbs (8.18\%) and climbers (2.52\%). But Baskaran et al. (2011) showed in

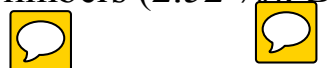

314 tropical forests of southern India during dry season revealed grasses were the major constituent

315 of FHA diet (28.6\%) followed by trees $(8.0 \%)$, shrubs $(5.6 \%)$ and herbs $(6.7 \%)$. Our findings

316 of the higher proportion of browse in FHA's diet supports the results of the feeding observations

317 made on this species in Bardia National Park, Nepal (Kunwar et al. 2016) and captive antelopes

318 in India (Solanki \& Naik 1998). Our results also show the high proportion of the Gramineae

319 family in the diet of this species similar to the findings of Kunwar et al. (2016). Although 
320 Baskaran et al. (2011) assert that FHA is the generalist in feeding strategy, our study showed that

321 it consumes more browse plant species than grasses in the winter season. According to Hofmann

322 (1989), concentrate feeders choose a high quality diet and show a remarkable degree of forage

323 selectivity. Some herbivores such as elephants graze in monsoon season and browse in the winter

324 season (Pradhan et al. 2008). Our results show that FHAs in Banke National Park may have the

325 plasticity to behave as concentrate feeders, canguming different proportions of various plant

326 species and growth form (grasses, forbs, shrubs, climbers, and trees).

327 During the monsoon season grass availability is high so the ungulates behave more like

328 pure grazers because they can find palatable orasses everywhere but they behave more like 329 browsers in winter, a season of resource scarce (Pradhan et al. 2008). Consistentwith that

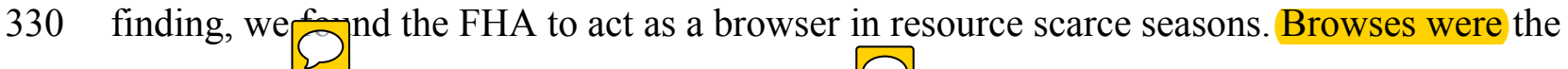

331 major contributors of FHA's diet in all seasons but the proportion of trees in the diet was high in

332 the winter season and low in summer and monsoon season (Kunwar et al. 2016). Similarly, we

333 found a high browse to grass ratio in winter season.

$334 \quad$ Micro-histological analysis method which we used for our study, includes multiple

335 successive sampling from the individuals, pellets and epidermis fragments. Sample size,

336 therefore, could affect the estimates in all consecutive sampling steps (Katona \& Altbäcker<smiles>[C+]1=CC=C1</smiles>

337 2002). So the larger sample size is required for the greater diversity of a species in the diet. In

338 our study, we randomly read 30 plant fragments per slide per pellet from 53 independent pellet

339 groups for determining FHA diet which we hope provides a reasonable sample size. Of the total

340 plant fragments, only $4.40 \%$ diet remained unidentified in this study. This percentage was $48 \%$

341 in Baskaran et al. (2011). In-vitro digestibility also greatly influenced the results of micro-

342 histological analysis particularly in the estimation of grass and forb content (Vavra \& Holechek 
343 1980). FHA eats fruits, flowers and fresh leaves (Berwick 1974; Baskaran et al. 2011) which are

344 highly digestible. Thus, this percentage of unidentified plants in the diet could be due to high

345 mastication and efficient digestion by the animal. Whe collected pellets and plants samples from

346 only one protected area during a single season. Much rigorous and detailed information can be

347 obtained from multi-season and multi-site study.

348 Overall, our results suggest that FHA has the feeding plasticity to adapt to resource

349 fluctuations. Future studies on nutrient content analysis of different diet plant species and causes

350 of changes in diet composition across seasons would be particularly useful for habitat

351 conservation and management. Based on the findings of this study, we recommend that dicots,

352 particularly fruit trees and shrubs, which are the major source of nutrients for FHA especially

353 during winter, be conserved and natural regeneration be promoted.

354

355

356

357

358

359

360

361

362

363

364

365

366

\section{Acknowledgement}

We thank the Department of National Parks and Wildlife Conservation of Nepal and Banke National Park for providing research permission. We acknowledge Prof. Dr. Santosh Rayamajhi, (Institute of Forestry, Tribhuvan University, Nepal) and Prof. Dr. Tej Bahadur Thapa (Central Department of Zoology, Tribhuvan University, Nepal) and Mr. Binod Shrestha for their guidance during the study and Central Department of Environmental Science, Tribhuvan University for providing the laboratory facility. We thank Dr. Hillary Young (Department of Ecology, Evolution, and Marine Biology, University of California, Santa Barbara, USA) for her contribution improve the English language and other technical issues during the manuscript revision phase. 
368

369

370

371

372

373

374

375

376

377

378

379

380

381

382

383

384

385

386

387

388

\section{Reference}

Ahrestani, F. S., Heitkönig, I. M. a., \& Prins, H. H. T. (2012). Diet and habitat-niche relationships within an assemblage of large herbivores in a seasonal tropical forest. Journal of Tropical Ecology, 28(2012), 385-394.

Ahrestani, F. S., M.A. Ignas, H., Hisashi, M., \& Prins, H. H. T. (2016). The ecology of large herbivores in south and southeast Asia. The Ecology of Large Herbivores in South and Southeast Asia. Springer Netherlands (pp. 99-120).

Aryal, A., Brunton, D., Ji, W. H., Yadav, H. K., Adhikari, B., \& Raubenheimer, D. (2012). Diet and habitat use of hispid hare Caprolagus hispidus in Shuklaphanta Wildlife Reserve, Nepal. Mammal Study, 37(2), 147-154.

Aryal, A., Coogan, S. C. P., Ji, W., Rothman, J. M., \& Raubenheimer, D. (2015b). Foods, macronutrients and fibre in the diet of blue sheep (Psuedois nayaur) in the Annapurna Conservation Area of Nepal. Ecology and Evolution, 5(18), 4006-4017.

Aryal, A., Panthi, S., Barraclough, R. K., Bencini, R., Adhikari, B., Ji, W., \& Raubenheimer, D. (2015a). Habitat selection and feeding ecology of dhole (Cuon alpinus) in the Himalayas. Journal of Mammalogy, 96(1), 47-53.

Baskaran, N. (1998). Ranging and resource utilization by Asian elephant (Elephas maximus Linn.) in Nilgiri Biosphere Reserve, South India. PhD dessertation. Bharathidasan University, Tiruchirapalli, India.

Baskaran, N., Kannan, V., Thiyagesan, K., \& Desai, A. A. (2011). Behavioural ecology of fourhorned antelope (Tetracerus quadricornis de Blainville, 1816) in the tropical forests of southern India. Mammalian Biology, 76(6), 741-747. 
390 Belovsky, G. E. (1997). Optimal foraging and community structure: The allometry of herbivore 391 food selection and competition. Evolutionary Ecology, 11, 641-672.

392 Berwick, S. H. (1974). The community of wild ruminants in the Gir forest ecosystem, India. PhD 393 dissertation. University of Michigan, USA.

394 Christianson, D., \& Creel, S. (2009). Effects of grass and browse consumption on the winter 395 mass dynamics of elk. Oecologia, 158, 603-613.

396 DNPWC. (2017a). Banke National Park. Retrieved August 20, 2017, from

397 http://dnpwc.gov.np/protected_areas/details/bankenationalpark

398 DNPWC. (2017b). Protected Areas of Nepal. Department of National Parks and Wildlife 399 Conservation, Kathmandu, Nepal.

400 Fritz, H., Garine-Wichatitsky, M. De, \& Letessier, G. (1996). Habitat use by sympatric wild and 401 domestic herbivores in an African savanna woodland: The influence of cattle spatial 402 behaviour. The Journal of Applied Ecology, 33(3), 589-598.

403 GoN. National Parks and Wildlife Conservation Act (1973). Nepal: Government of Nepal, Nepal $404 \quad$ law commission.

405 Hofmann, R. R. (1989). Evolutionary steps of ecophysiological adaptation and diversification of 406 ruminants: a comparative view of their digestive system. Oecologia, 78, 443-457.

407 IUCN SSC Antelope Specialist Group. (2017). Tetracerus quadricornis. International Union for $408 \quad$ Nature Conservaion.

409 Jung, T. S., \& Kukka, P. M. (2016). Influence of habitat type on the decay and disappearance of 410 elk Cervus canadensis pellets in boreal forest of northwestern Canada. Wildlife Biology, $41122(4), 160-166$

412 Jung, T. S., Stotyn, S. A., \& Czetwertynski, S. M. (2015). Dietary overlap and potential 
competition in a dynamic ungulate community in Northwestern Canada. Journal of Wildlife Management, 79(8), 1277-1285.

415 Katona, K., \& Altbäcker, V. (2002). Diet estimation by faeces analysis: Sampling optimisation 416 for the European hare. Folia Zoologica, 51(1), 11-15.

417 Klaus-Hügi, C., Klaus, G., Schmid, B., \& König, B. (1999). Feeding ecology of a large social 418 antelope in the rainforest. Oecologia, 119, 81-90.

419 Krishna, Y. C., Clyne, P. J., Krishnaswamy, J., \& Kumar, N. S. (2009). Distributional and 420 ecological review of the four horned antelope, Tetracerus quadricornis. Mammalia, 73(1), $421 \quad 1-6$.

422 Krishna, Y. C., Krishnaswamy, J., \& Kumar, N. S. (2008). Habitat factors affecting site 423 occupancy and relative abundance of four-horned antelope. Journal of Zoology, 276(1), 63424 70.

Kunwar, A., Gaire, R., Pokharel, K. P., Baral, S., \& Thapa, T. B. (2016). Diet of the four-horned antelope Tetracerus quadricornis (De Blainville, 1816) in the Churia hills of Nepal. Journal of Threatened Taxa, 8(5), 8745-8755.

Leslie, J. D., \& Sharma, K. (2009). Tetracerus quadricornis (Artiodactyla: Bovidae). Mammalian Species, 843, 1-11.

Mishra, C., Van Wieren, S. E., Ketner, P., Heitkönig, I. M. A., \& Prins, H. H. T. (2004). Competition between domestic livestock and wild bharal Pseudois nayaur in the Indian Trans-Himalaya. Journal of Applied Ecology, 41, 344-354.

433 Nagarkoti, A., \& Thapa, T. (2007). Food habits of barking deer (Muntiacus muntjac) in the 434 middle hills of Nepal. Hystrix, the Italian Journal of Mammalogy, 18(1), 77-82.

435 Norbury, G. L. (1988). Microscopic analysis of herbivore diets- a problem and a solution. 
Australian Wildlife Research, 15, 51-57.

437 Owen-Smith, R. N. (1992). Megaherbivores: The influence of very large body size on ecology. 438 Cambridge University Press.

439 Panthi, S. (2011). Feeding Ecology, Habitat Preference and Distribution of Red Panda (Ailurus 440 fulgens fulgens) in Dhopatan Hunting Reserve, Nepal. BSc thesis. Tribhuvan University, $441 \quad$ Instrtute of Forestry, Pokhara, Nepal.

442 Panthi, S., Aryal, A., Raubenheimer, D., Lord, J., \& Adhikari, B. (2012). Summer diet and 443 distribution of the red panda (Ailurus fulgens fulgens) in Dhorpatan hunting reserve, Nepal. $444 \quad$ Zoological Studies, 51(5), 701-709.

445 Panthi, S., Coogan, S. C. P., Aryal, A., \& Raubenheimer, D. (2015). Diet and nutrient balance of 446 red panda in Nepal. The Science of Nature, 102, 54.

447 Parker, K. L., Barboza, P. S., \& Gillingham, M. P. (2009). Nutrition integrates environmental 448 responses of ungulates. Functional Ecology, 23, 57-69.

449 Pekins, P. J., Smith, K. S., \& Mautz, W. W. (1998). The energy cost of gestation in white-tailed $450 \quad$ deer. Canadian Journal of Zoology, 76(6), 1091-1097.

451 Pokharel, K. P. (2010). Factors influencing the spatial distribution patterns of the Four-Horned 452 Antelope in Babai Valley, Bardia National Park, Nepal. MSc thesis. University of Freiburg, 453 Germany.

454 Pokharel, K. P., Ludwig, T., \& Storch, I. (2015b). Spatial niche partitioning in sub-tropical 455 solitary ungulates: Four-horned antelope and barking deer in Nepal. PLoS ONE, 10(2), 145616.

457 Pokharel, K. P., Yohannes, E., Salvarina, I., Storch, I., Hutchinson, G., Holt, R., ... Zar, J. 458 (2015a). Isotopic evidence for dietary niche overlap between barking deer and four-horned 

antelope in Nepal. Journal of Biological Research-Thessaloniki, 22(1), 6.

460 Pradhan, N. M. B., Wegge, P., Moe, S. R., \& Shrestha, A. K. (2008). Feeding ecology of two 461 endangered sympatric megaherbivores: Asian elephant Elephas maximus and greater one462 horned rhinoceros Rhinoceros unicornis in lowland Nepal. Wildlife Biology, 14(1), 147463 154.

464 R Core Team. (2013). R: A language and environment for statistical computing. Retrieved 465 January 19, 2018, from http:/www.blopig.com/blog/2013/07/citing-r-packages-in-yourthesispaperassignments/

467

468

469

470

471

472

473

474

475

476

477

478

479

480

481

Rahmani, A. . (2001). Antelopes. Part 4: North Africa, the Middle East, and Asia. Mallon, D.P. \& S.C. Kingswood (compilers). Global survey and regional action plans. SSC Antelope Specialist Group. IUCN, Gland, Switzerland and Cambridge, UK. viii.

Schemnitz, S. D. (1980). Wildlife management technique manual. 4th ed. Wildlife Society: Washington, DC

Sharma, K., Chundawat, R. S., Van Gruisen, J., \& Rahmani A. R. (2013). Understanding the patchy distribution of four-horned antelope Tetracerus quadricornis in a tropical dry deciduous forest in Central India. Journal of Tropical Ecology, 30(1), 45-54.

Sharma, K., Rahmani, A. A. R. A., \& Chundawat, R. S. (2009). Natural history observations of the Four-horned antelope Tetracerus quadricornis. Journal of the Bombay Natural History Society, 106(1), 72-82.

Shrestha, R., Koirala, R. A., \& Wegge, P. (2005). Summer diets of wild and domestic ungulates in Nepal Himalaya. Journal of Zoology, 266, 111-119.

Sokos, C., Andreadis, K., \& Papageorgiou, N. (2015). Diet adaptability by a generalist herbivore: The case of brown hare in a mediterranean agroecosystem. Zoological Studies, 54:27 
482 Solanki, G., \& Naik, R. (1998). Grazing interactions between wild and domestic herbivores. $483 \quad$ Small Ruminant Research, 27(3), 231-235.

484 Styles, C. V, \& Skinner, J. D. (1997). Seasonal variations in the quality of mopane leaves as a 485 source of browse for mammalian herbivores. African Journal of Ecology, 35, 254-265.

486 Sukumar, R. (1989). The Asian elephant: Ecology and management. Cambridge University 487 Press:New York.

488 Suryawanshi, K. R., Bhatnagar, Y. V., \& Mishra, C. (2010). Why should a grazer browse?

489 Livestock impact on winter resource use by bharal Pseudois nayaur. Oecologia, 162, 453$490 \quad 462$.

491 UNEP-WCMC\& IUCN. (2017). Protected planet: Protected areas of Nepal; The world database 492 on protected areas (WDPA)/the global database on protected areas management 493 effectiveness (GD-PAME), Cambridge, UK: UNEP-WCMC and IUCN. Retrieved August 4942017 , from www.protectedplanet.net.

495 Valeix, M., Loveridge, A. J., Chamaille-Jammes, S., Davidson, Z Murindagomo, F., Fritz, H., 496 \& Macdonald, D. W. (2009). Behavioural adjustments of Arfican herbivores to predation 497 riks by lions: spatiotemporal variations influence habitat use. Ecology, 90(1), 23-30.

498 Vavra, M., \& Holechek, J. L. (1980). Factors influencing microhistologial analysis of herbivore 499 diets. Journal of Range Management, 33(5), 317-373.

500 Wangchuk, T. R., Wegge, P., \& Sangay, T. (2016). Habitat and diet of Bhutan takin Budorcas 501 taxicolor whitei during summer in Jigme Dorji National Park, Bhutan. Journal of Natural $502 \quad$ History, 50(11-12), 759-770.

503 Wilsey, B. J. (1996). Variation in use of green flushes following burns among African ungulate 504 species: The importance of body size. African Journal of Ecology, 34, 32-38. 


\section{Table $\mathbf{1}$ (on next page)}

Percentage compositions of various plant categories identified in pellets of FHA 


\begin{tabular}{|c|c|c|c|c|}
\hline Family & Species & Class & Growth form & Percent occurrence \\
\hline \multirow[t]{9}{*}{ Gramineae } & Hemarthria compressa & Monocot & Forb & 6.29 \\
\hline & Imperata cylindrica & Monocot & Grass & 4.09 \\
\hline & Eulaliopsis binata & Monocot & Grass & 3.14 \\
\hline & Bambusa vulgare & Monocot & Tree & 2.83 \\
\hline & Thysanolaena maxima & Monocot & Shrub & 2.83 \\
\hline & Themeda triandra & Monocot & Grass & 2.52 \\
\hline & Heteropogon contortus & Monocot & Grass & 2.2 \\
\hline & Cynodon dactylon & Monocot & Forb & 1.89 \\
\hline & Digitaria spp. & Monocot & Grass & 1.89 \\
\hline Gramineae total & & & & 27.68 \\
\hline \multirow[t]{3}{*}{ Compositae } & Terminalia alata & Dicot & Tree & 4.4 \\
\hline & Terminalia chebula & Dicot & Tree & 2.52 \\
\hline & Terminalia belerica & Dicot & Tree & 1.57 \\
\hline Compositae total & & & & 8.49 \\
\hline \multirow[t]{2}{*}{ Euphorbiaceae } & Phyllanthus emblica & Dicot & Shrub & 6.92 \\
\hline & Mallotus philippensis & Dicot & Tree & 5.03 \\
\hline Euphorbiaceae total & & & & 11.95 \\
\hline \multirow[t]{2}{*}{ Leguminoseae } & Acacia catechu & Dicot & Tree & 4.72 \\
\hline & Bauhinia vahlii & Dicot & Climber & 2.52 \\
\hline Leguminoseae total & & & & 7.24 \\
\hline Rubiceae & Xeromphis spinosa & Dicot & Tree & 5.97 \\
\hline Rhamnaceae & Zizyphus mauritiana & Dicot & Tree & 4.4 \\
\hline Oleaceae & Nyctanthes arbortristis & Dicot & Shrub & 3.77 \\
\hline Apocynaceae & Carissa spinarum & Dicot & Shrub & 3.46 \\
\hline Dipteriocarpaceae & Shorea robusta & Dicot & Tree & 3.46 \\
\hline Lythraceae & Woodfordia fruiticosa & Dicot & Shrub & 2.83 \\
\hline Anacardiaceae & Buchanania lanzans & Dicot & Tree & 2.52 \\
\hline Myrtaceae & Eugenia spp. & Dicot & Tree & 2.52 \\
\hline Sapindaceae & Schleichera oleosa & Dicot & Tree & 2.52 \\
\hline Rutaceae & Aegle marmelos & Dicot & Tree & 2.2 \\
\hline Tilaceae & Grewia spp. & Dicot & Shrub & 2.2 \\
\hline Myrsinaceae & Myrsine semiserrata & Dicot & Tree & 1.89 \\
\hline Liliaceae & Asparagus phillipensis & Monocot & Shrub & 1.57 \\
\hline Verbenaceae & Clerodendrum viscosum & Dicot & Shrub & 0.94 \\
\hline Unidentified & & & & 4.4 \\
\hline Identified total & & & & 95.6 \\
\hline Dicot total & & & & 66.36 \\
\hline Monocot total & & & & 29.25 \\
\hline
\end{tabular}


Tree total

Shrub total

Grass total

Forb total

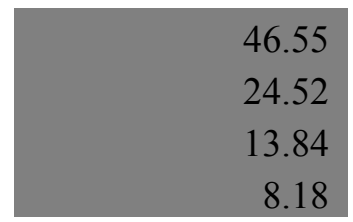

Total

100

2 


\section{Figure 1}

(2)

The small map with boundary of Nepal is showing the protected areas of Nepal.

Different colors are denoting the different categories of the protected areas. The map with large scale is the study area, Banke National Park, which is showing the core zone and buffer zone of National Park and locations of sample collection (source of shape file: UNEP-WCMC\& IUCN, 2017).

\section{Legend}

- Location of Sample Collection

Buffer Zone

Core Zone
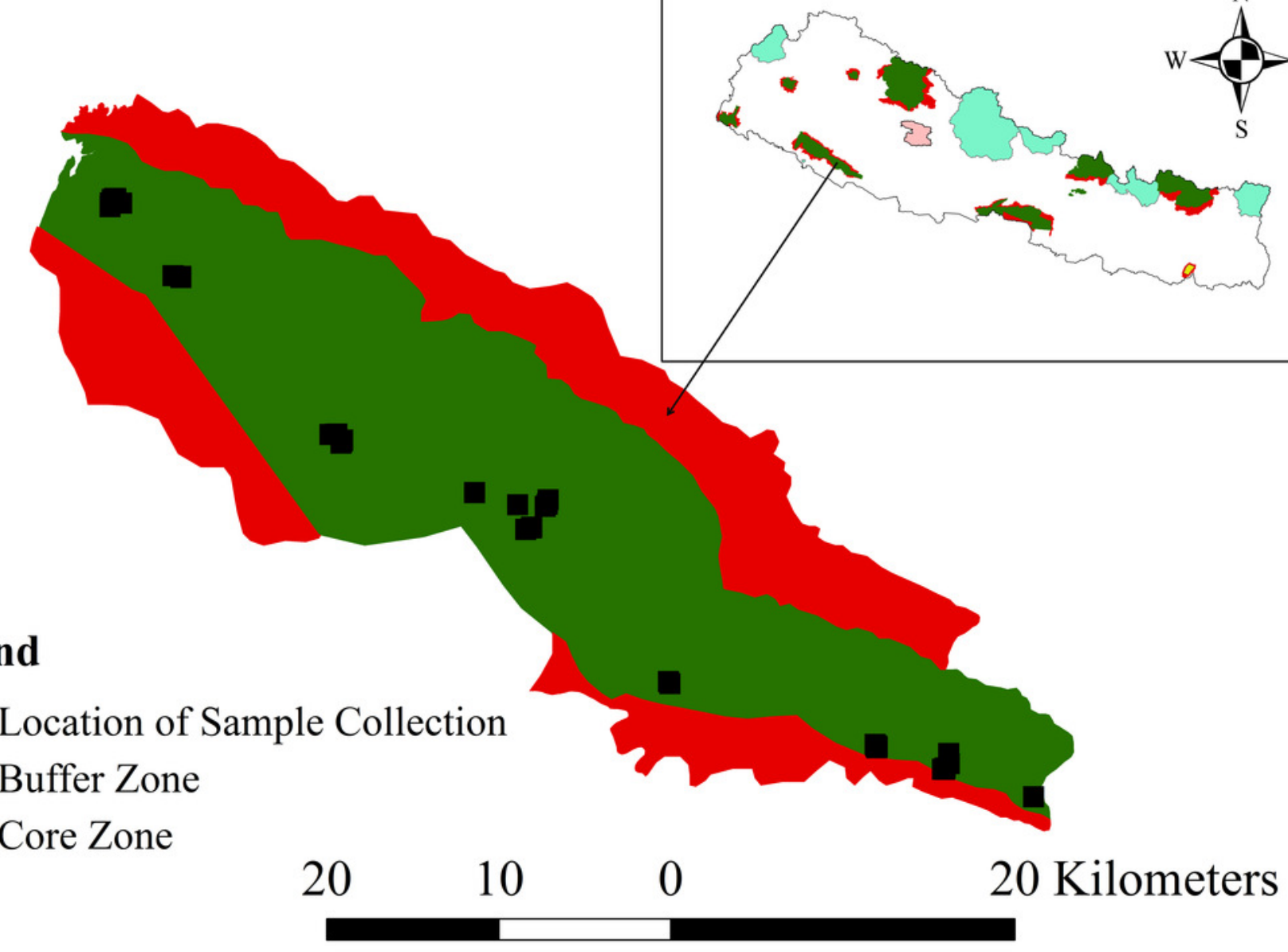